\title{
IN-SITU THIN FILM GROWTH OF PbTiO3 BY MULTI TARGET SPUTTERING
}

\author{
THOMAS MAEDER AND PAUL MURALT, \\ Laboratoire de Céramique, Swiss Federal Institute of Technology (EPFL), \\ Lausanne, Switzerland.
}

\begin{abstract}
The in-situ reactive sputter deposition of $\mathrm{PbTiO}_{3}$ on $\mathrm{Pt} / \mathrm{Ti} / \mathrm{SiO}_{2} / \mathrm{Si}$ from two metallic targets was investigated. A minimal lead oxide flux of two to three times the titanium oxide flux is needed in order to obtain stoichiometric films with the perovskite structure. For higher fluxes, the $\mathrm{Pb} / \mathrm{Ti}$ ratio in the film stays at the stoichiometric value 1; the orientation changes from random to $\langle 100\rangle$; and the film morphology transforms from a rough to a smooth polycrystalline film. The obtained dielectric constants vary between 40 and 150, the losses between 2 and $4 \%(10 \mathrm{kHz})$. The method could be extended to $\mathrm{PbZr}_{\mathrm{x}} \mathrm{Ti}_{1-\mathrm{x}} \mathrm{O}_{3}$ for $\mathrm{x} \leq 0.7$. The orientation is lost when the Pt electrodes are replaced by $\mathrm{RuO}_{2}$ electrodes.
\end{abstract}

\section{INTRODUCTION}

There are several methods for the sputter deposition of ferroelectric oxide films such as $\mathrm{PbTiO}_{3}(\mathrm{PT})$. Single sources, with a two-metal segmented target ${ }^{1}$, or with a composite oxide target ${ }^{2}$, as well as cosputtering with metal or oxide targets, have been applied. Three different geometries exist in the latter case: static cosputtering with focused sources, facing target sputtering ${ }^{3}$, and simultaneous sputtering onto a rotating substrate holder, where the substrate passes the two sources alternately ${ }^{4,5,6}$. In addition one has the choice of in-situ deposition at elevated temperatures or a deposition at moderate temperatures followed by an anneal. In the latter case the as deposited film needs to have excess lead ( $10 \%$ or more) to compensate for the reevaporation of lead during the post-deposition anneal. This lead loss causes pits and holes along grain boundaries ${ }^{7}$. For this reason we decided to apply an in-situ technique. Since the $\mathrm{Pb}$ to $\mathrm{Ti}$ ratio needed is expected to depend on temperature and sputter conditions the multi-source target approach with single metal targets is much more practical. In the past the in-situ fabrication often failed because the electrodes (usually $\mathrm{Pt} / \mathrm{Ti}$ ) did not stand the high thermal budget of the deposition process. This problem was solved by indroducing an additional oxide barrier between $\mathrm{Ti}$ and $\mathrm{Pt}^{8}$.

\section{EXPERIMENTAL}

The films were grown in a NORDIKO 2000 sputter-system with three $100 \mathrm{~mm}$ magnetron sources on the bottom of the chamber. The Pb target was mounted on a $\operatorname{rf}(13.56 \mathrm{MHz})$ source, the Ti target on a dc source. The oxidation of the $\mathrm{Pb}$ target was achieved with less oxygen in case of $\mathrm{rf}$ excitation. A careful anode design turned out to be necessary to obtain reproducible results and to avoid flaking and particles. Above about 8 mtorr sputter gas pressure, Ar could no longer be used because the $\mathrm{Pb}$ target started to eject particles, leaving holes in the target surface. The cathode (self bias) dc voltages were in the range of 250 to $400 \mathrm{~V}$ for $\mathrm{Pb}(50$ to $150 \mathrm{~W})$ and 350 to $500 \mathrm{~V}$ for Ti (usually $500 \mathrm{~W}$ ). The resulting $\mathrm{TiO}_{2}$ dynamic rates were $1.3 \mathrm{~nm} / \mathrm{min}$ in $\mathrm{Ar} / \mathrm{O}_{2}$ mixture and $1.5 \mathrm{~nm} / \mathrm{min}$ in pure $\mathrm{O}_{2}$. The $\mathrm{PbO}$ sputter yield increased strongly with increasing Ar flow. The maximum flux was 2 (no Ar) to $7\left(\mathrm{Ar} / \mathrm{O}_{2}=1\right)$ times the $\mathrm{TiO}_{2}$ flux.

The wafers were mounted on the disk-like substrate carrier, face down. The dynamic rate obtained with the rotating substrate carrier was 10 times lower than the static rate. The rotation speed was usually 6 $\mathrm{rpm}$, which roughly corresponds to a monolayer of PT per cycle. The substrate was heated indirectly 
by radiation from the 4" steel substrate holder. Reasonable assumptions of the involved emissivities yield an absolute substrate temperature which is 10 to $15 \%$ lower than the measured temperature of the substrate holder. The temperatures given in this paper are $90 \%$ of the measured ones.

The $\mathrm{RuO}_{2}$ electrodes were deposited with a dc magnetron at $690 \mathrm{~K}$ in a pure oxygen sputter gas of 10 mtorr. The film was crystalline and did not need any post-anneal. As in the case of Pt, we first deposited a thin layer of $\mathrm{Ti}$, followed by a thin layer of $\mathrm{TiO}_{2}$ as adhesion layers.

\section{RESULTS ON THIN FILM GROWTH DYNAMICS}

We measured the deposition rate as a function of the $\mathrm{Pb}$ cathode power, while keeping the power of the Ti cathode constant. For low $\mathrm{PbO}$ fluxes most of the $\mathrm{PbO}$ is absorbed in the film. For higher fluxes the $\mathrm{PbO}$ absorption rate saturates at the $\mathrm{TiO}_{2}$ condensing rate, i.e. stoichiometric PT films are obtained, as was checked by means of EDS. The excess amount of $\mathrm{PbO}$ is reevaporated. Figure 1 shows the saturation behaviour of the $\mathrm{Pb}$ content calculated from the rate and the theoretical densities of $\mathrm{TiO}_{2}, \mathrm{PbO}$ and PT. The saturation at stoichiometry was earlier observed for the coevaporation of $\mathrm{TiO}_{2}$ and $\mathrm{PbO}$ at temperatures above $870 \mathrm{~K}^{9}$ and for sputtering at $900 \mathrm{~K}^{5}$. In contrast to ref. 5, our films on $\mathrm{Pt}$ electrodes showed a preferred $<100>$ orientation in the saturated region.

The film orientation seems to be driven by the optimal $\mathrm{PbO}$ chemisorption: At lower $\mathrm{PbO}$ fluxes (slight understoichiometry) the preferred orientations are $\langle 110\rangle$ and $\langle 111\rangle$, which allow to chemisorb more than one $\mathrm{PbO}$ per $\mathrm{TiO}_{2}$ on the top layer; whereas at excess $\mathrm{PbO}$ flux the $<100>$ orientation is preferred. In the perfect perovskite structure, the latter terminates with a pure $\mathrm{PbO}$ layer, from which all excess $\mathrm{PbO}$ is reevaporated.

\section{Relative PbO content vs. flux of PbO}

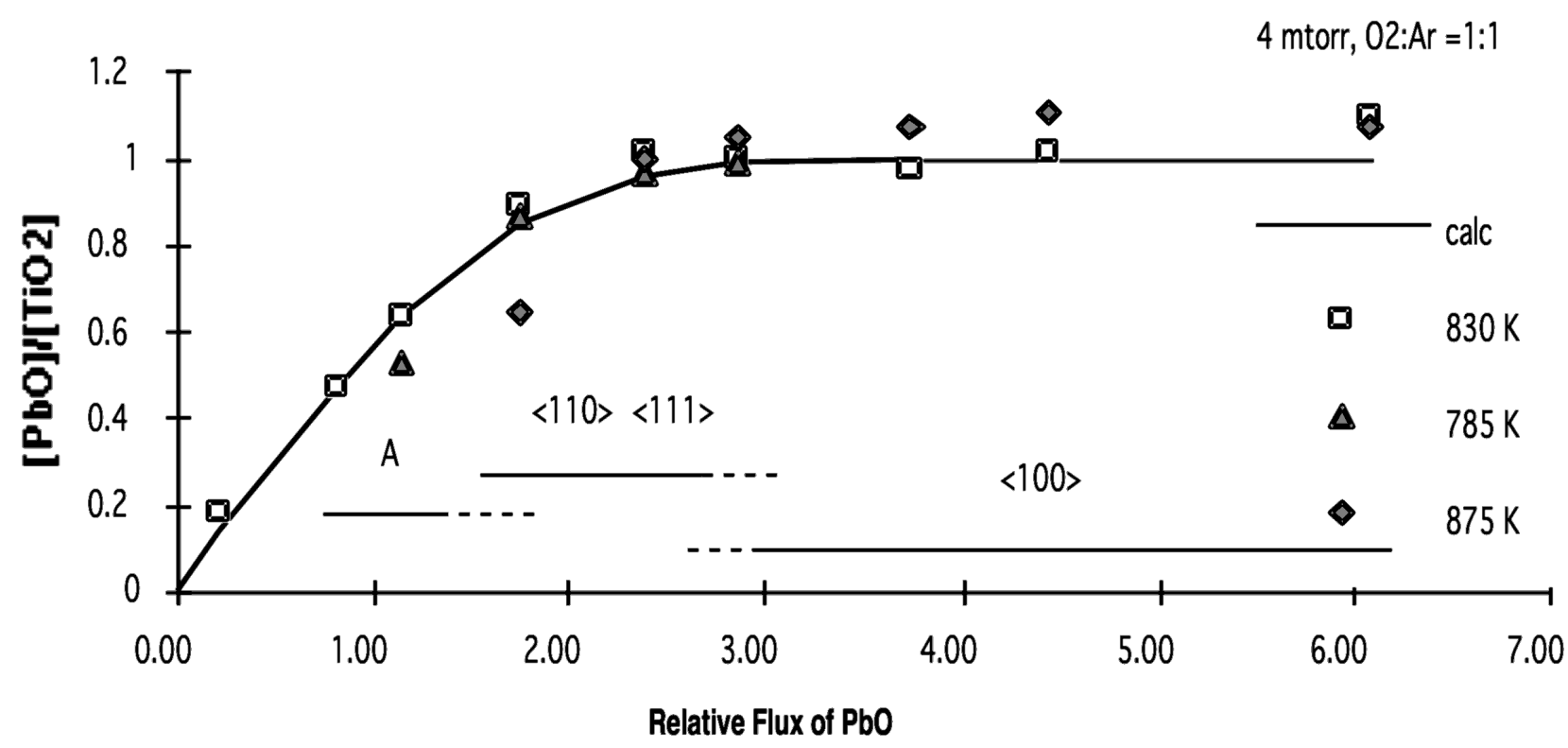

Fig. 1: The PbO content of films grown on Pt, as calculated from the rate increase and theoretical densities, vs. the PbO flux devided by the $\mathrm{TiO}_{2}$ flux. The inserted lines indicate the range of the different film orientations, A stands for amorphous. The $\mathrm{PbO}$ content of the film has been derived from the rate, taking into account the standard densities of $\mathrm{TiO}_{2}, \mathrm{PbO}$ and PT. 


\section{Mathematical description:}

A simplified mathematical description of the lead content is obtained, if we assume that $\mathrm{Pb}$ can occupy one site per $\mathrm{Ti}$ only. During the deposition of $\mathrm{PbO}$ on a monolayer of $\mathrm{TiO}_{2}$, the fraction $\Theta$ of occupied $\mathrm{PbO}$ sites increases therefore to a maximum of 1 . The ad-atoms $(\mathrm{Pb})$ or ad-molecules $(\mathrm{PbO})$ of density $\mathrm{n}$ that are mobile on the surface of the growing film are desorbed from the already occupied sites at a rate of $n \Theta \delta_{n}$, desorbed from the non-occupied sites at a rate of $n(1-\Theta) \delta_{b}$, and bound at a rate of $n(1-\Theta) b$. It is further assumed that the desorption and chemisorption rates, $\delta_{\mathrm{n}}, \delta_{\mathrm{b}}$ and $\mathrm{b}$, do not depend on $\Theta$. The rate equation for the ad-atoms now becomes, in analogy to the case of only one type of atom (see, e.g., references 10 and 11):

$$
\frac{d n}{d t}=P-v\left[\Theta \delta_{v}+(1-\Theta)\left(\beta+\delta_{\beta}\right)\right]
$$

Taking the steady state solution $(\mathrm{dn} / \mathrm{dt}=0)$ for the ad-atom density one arrives at a simple integrable differential equation for $\Theta$ :

$$
\frac{d \Theta}{\delta \tau}=v(1-\Theta) \beta=\frac{(1-\Theta) P \beta}{\Theta \delta_{v}+(1-\Theta)\left(\beta+\delta_{\beta}\right)}
$$

The curve in fig. 1 was obtained with $\delta_{\mathrm{n}}=0.4 \cdot \mathrm{b}$ and $\delta_{\mathrm{b}}=0.6 \cdot \mathrm{b}$. These quantities are functions of temperature. One would expect ${ }^{10,11}$ :

$$
\delta_{n}=v_{a} \cdot e^{-E_{a} / k T s}, \quad \delta_{b}=v_{a} \cdot e^{-\left(E_{a}+E_{b}\right) / k T s}
$$

$\mathrm{T}_{\mathrm{S}}$ is the surface temperature, $v_{\mathrm{a}}$ the vibration frequencies of the ad-atoms, $\mathrm{E}_{\mathrm{a}}$ the adsorption energy on the non-bonding sites and $\mathrm{E}_{\mathrm{b}}$ the energy necessary to move an adatom from a bonding to a non-bonding site. Unlike the results obtained with evaporation ${ }^{9}$, where the plateau at stoichiometry is not possible below $870 \mathrm{~K}$, we see the plateau still $100 \mathrm{~K}$ below that value when 4 mtorr of mixed sputter gas is applied. Most probably the desorption rate is enhanced by fast neutrals (Ar), kinetic energy of the arriving $\mathrm{PbO}$ molecules, and electron and ion impact. This explanation is also supported by the observation that at 16 mtorr pure oxygen, the inital slope of the curve is steeper than that shown in fig. 1 for 4 mtorr.

Of course, the reaction of $\mathrm{PbO}$ and $\mathrm{TiO}_{2}$ to form the perovskite structure occurs not only at the surface. There is some diffusion from the surface into the bulk. We determined the diffusion depth by reducing the rotation speed of the carrier, thus depositing thicker films in one turn. The maximum thickness allowing good interdiffusion is about 10 monolayers, above which the rate drops considerably, i.e. less and less $\mathrm{PbO}$ is chemisorbed. In case of understoichiometry, occupied $\mathrm{PbO}$ sites become thus empty again by the diffusion of $\mathrm{PbO}$ or $\mathrm{Pb}$ into the next lower layers. This would allow the system to reach stoichiometry with lower fluxes of $\mathrm{PbO}$.

\section{THIN FILM PROPERTIES}

\section{Film structure, composition and and surface morphology}

It is a common feature of all our X-ray Bragg spectra of PT that the 001 and 101 peaks are much stronger than 100 and 110, even for almost randomly oriented films (figs. 2 and 3). This may be caused by the anisotropic stress building up at the cubic to tetragonal phase transition just below the deposition temperature, at which $\mathrm{c}$ grows and a shrinks. Films grown on $\mathrm{Pt}$ show generally a better $<100>$ orientation than the films grown on $\mathrm{RuO}_{2}$. From the width and the intensity of the $\mathrm{x}$-ray diffraction Bragg peaks we could conclude that the optimal temperature for the growth of PT was between 800 and $900 \mathrm{~K}$. This temperature range is less than the $930 \mathrm{~K}$ given in ref. 6 and more than the $720 \mathrm{~K}$ given in ref. 4 as ideal deposition temperatures. 


\section{X-ray Bragg Reflections of PT on Pt}

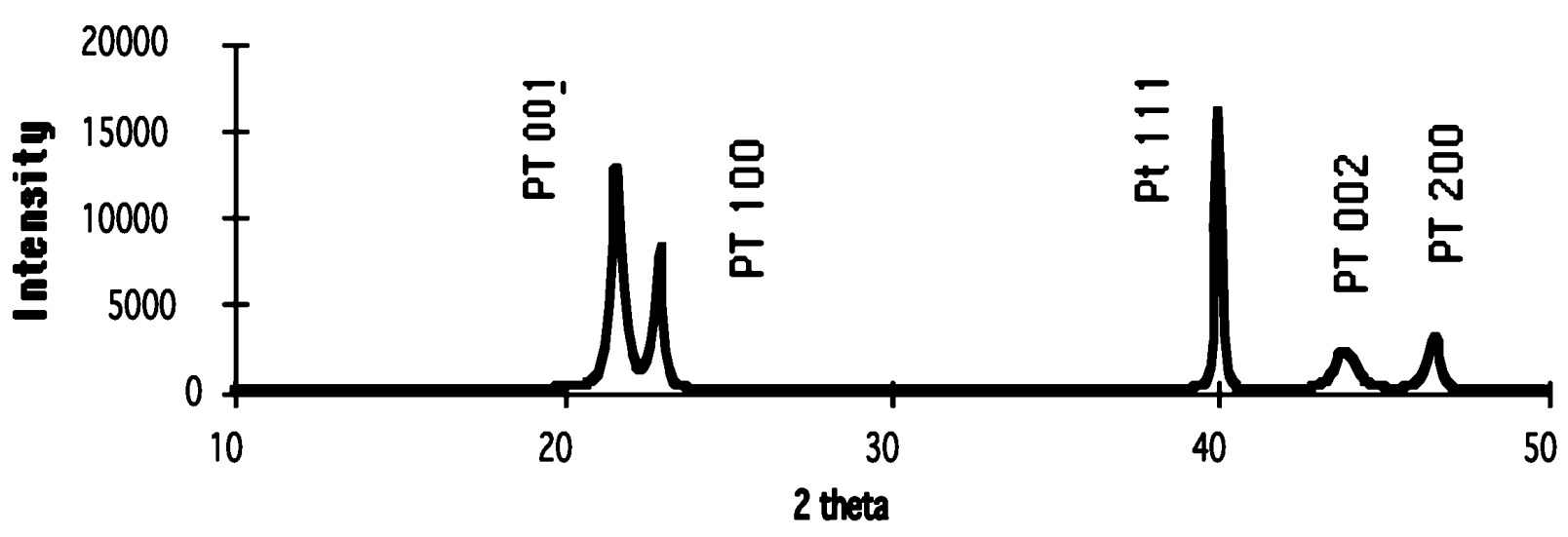

Fig.2: Spectrum of x-ray Bragg peaks for PT fabricated at $830 \mathrm{~K}, 4 \mathrm{mtorr}$, mixed sputter gas and $100 \mathrm{~W}$ power at the lead source. The ratio of 001 to 100 orientation is approximately $3: 1$.

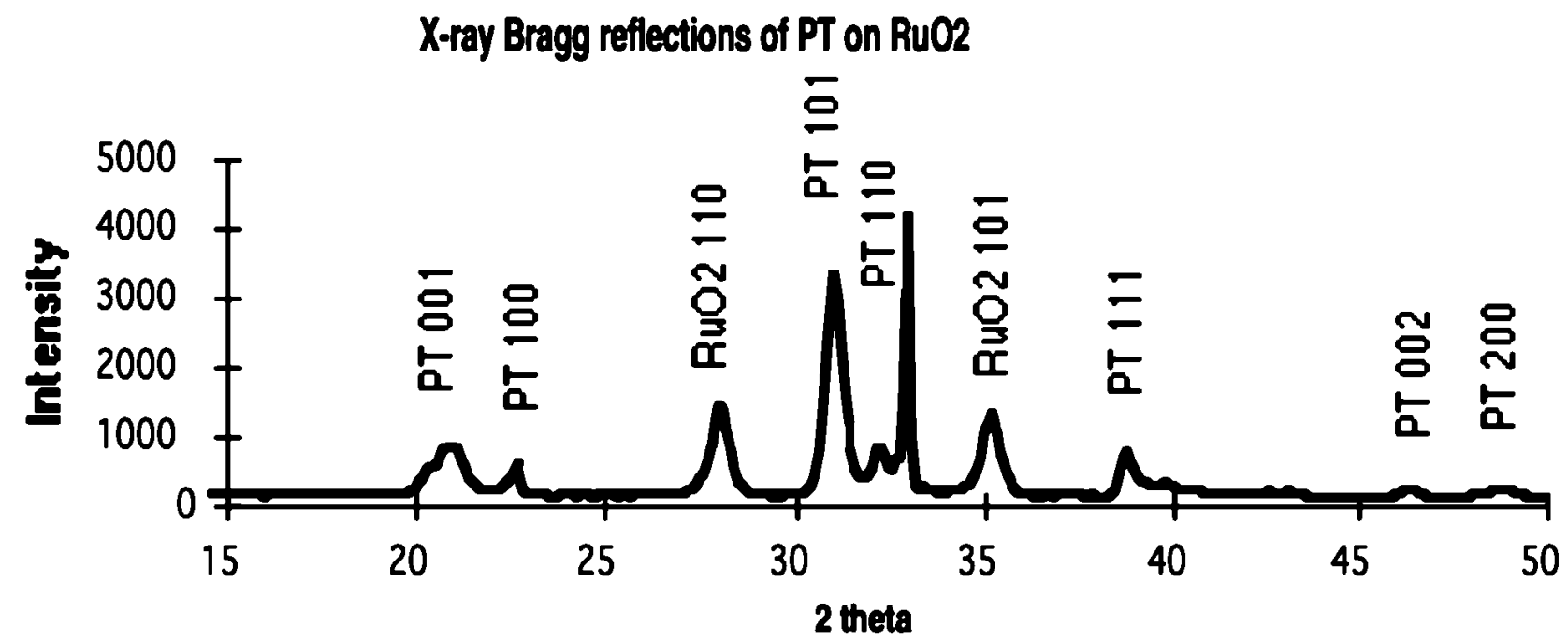

Fig.3: Spectrum of x-ray Bragg peaks for PT fabricated on $\mathrm{RuO}_{2}$ at $830 \mathrm{~K}, 16$ mtorr $\mathrm{O}_{2}$ and $100 \mathrm{~W}$ power at the lead source.

SEM inspection showed that the films are essentially defect free. The surface morphology depends strongly on the $\mathrm{PbO}$ flux. At high fluxes the surface is smooth. The $<100>$ oriented grains have an average dia of $200 \mathrm{~nm}$ and show no facets in oblique directions. Near the critical fluxes, where the films are randomly oriented, the surface is rather rough. Oblique 100 facets of 110 oriented grains can be identified. This trend is consistent with RHEED studies made at reactive evaporated films of $\mathrm{BaTiO}_{3}$ and $\mathrm{SrTiO}_{3}{ }^{10}$. There it was found that the migration of $\mathrm{Ba}$ and $\mathrm{Sr}$ was promoted by Ti free surfaces, obtained by an alternate supply of A and B atoms. This had lead to a reduction of the surface step densisty and thus to smoother films. It is therefore possible that dynamic sputtering yields smoother films than static sputtering.

$\mathrm{The} \mathrm{Pb}$ to Ti ratio of samples in the plateau region was measured with EDS. It was found to be 1 within the error of the method $(2 \%)$. The ratio determined from the rates, as given in fig. 1 , deviate with up to $9 \%$ from 1 . This can be explained by densities lower than the theoretical ones and by the error of the thickness measurement. 


\section{Dielectric properties}

The permitivity and the loss have been measured on a HP 4194A impedance meter. The frequency dependence of one sample is shown in fig.4. The majority of the values of the dielectric constant are within the range given for monocrystal values by Li et.al. ${ }^{13}: \varepsilon_{11}=101, \varepsilon_{33}=34$ at constant strain, and 130 and 80 at constant stress respectively. Accordingly, the low values of the permittivity are caused by stress in the film. We found indeed a correlation between permittivity and film orientation. Random orientation and a high ratio of $\mathrm{I}(001) / \mathrm{I}(100)$ lead to low values of $\varepsilon$ (40 to 70$)$, whereas oriented films with $\mathrm{I}(001) / \mathrm{I}(100)<3$ lead to higher values $(\varepsilon=120$ to 150$)$.

The loss scattered between 2.6 and $4.6 \%$, depending on process conditions. Some of the process parameters have a clear impact on the loss. Its increase is observed with increasing substrate bias and increasing power at the lead source.

The yield of the capacitors with a diameter of $0.6 \mathrm{~mm}$ were between 30 and $90 \%$ and showed the following trends: The yield increases with higher pressure, with lower power on the lead source and with increasing rf bias on the substrate. At 4 mtorr the mixed gas gave a higher yield than pure oxygen.

\section{Dielectric Constant and Loss of PT vs \\ Frequency}

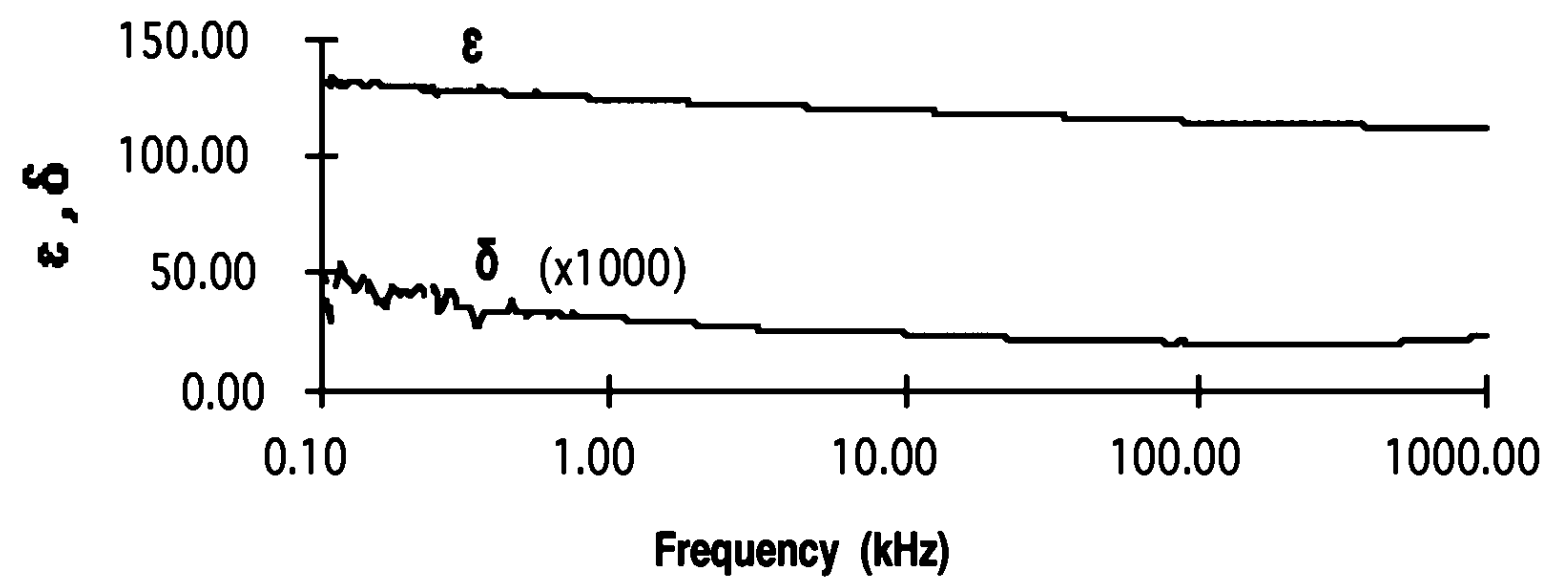

Fig.4: Dielectric constant and loss of a sample of PT, fabricated at $830 \mathrm{~K}, 4 \mathrm{mtorr}$ Ar and oxygen mixed, $100 \mathrm{~W}$ rf power at the lead source and $500 \mathrm{~W}$ de power at the Ti source.

\section{EXTENSION OF THE METHOD TO PZT}

The behaviour of the PZ system is much different from that of the PT system. It was not possible to grow PZ films with the same method and in the same temperature range as $\mathrm{PT}$. $\mathrm{PbO}$ and $\mathrm{ZrO}_{2}$ did not form a compound. Only a small fraction of $\mathrm{Pb}$ stayed in the film, which turned out to be essentially zirconia of tetragonal symmetry. However, the method worked in the range between 0 and $53 \% \mathrm{Zr}$ content. Once the perovskite was formed, it was possible to decrease the Ti flux. In this way we could extend the limit to $70 \% \mathrm{Zr}$. The hysteresis curve of such a bilayer film is shown in fig. 5. The lead saturation at stoichiometric PZT is, to our knowledge, a new result. In ref. 6 a saturation at $50 \%$ excess lead is reported for the cosputtering technique with oxide targets. 


\section{Hysteresis Curve of PZT}

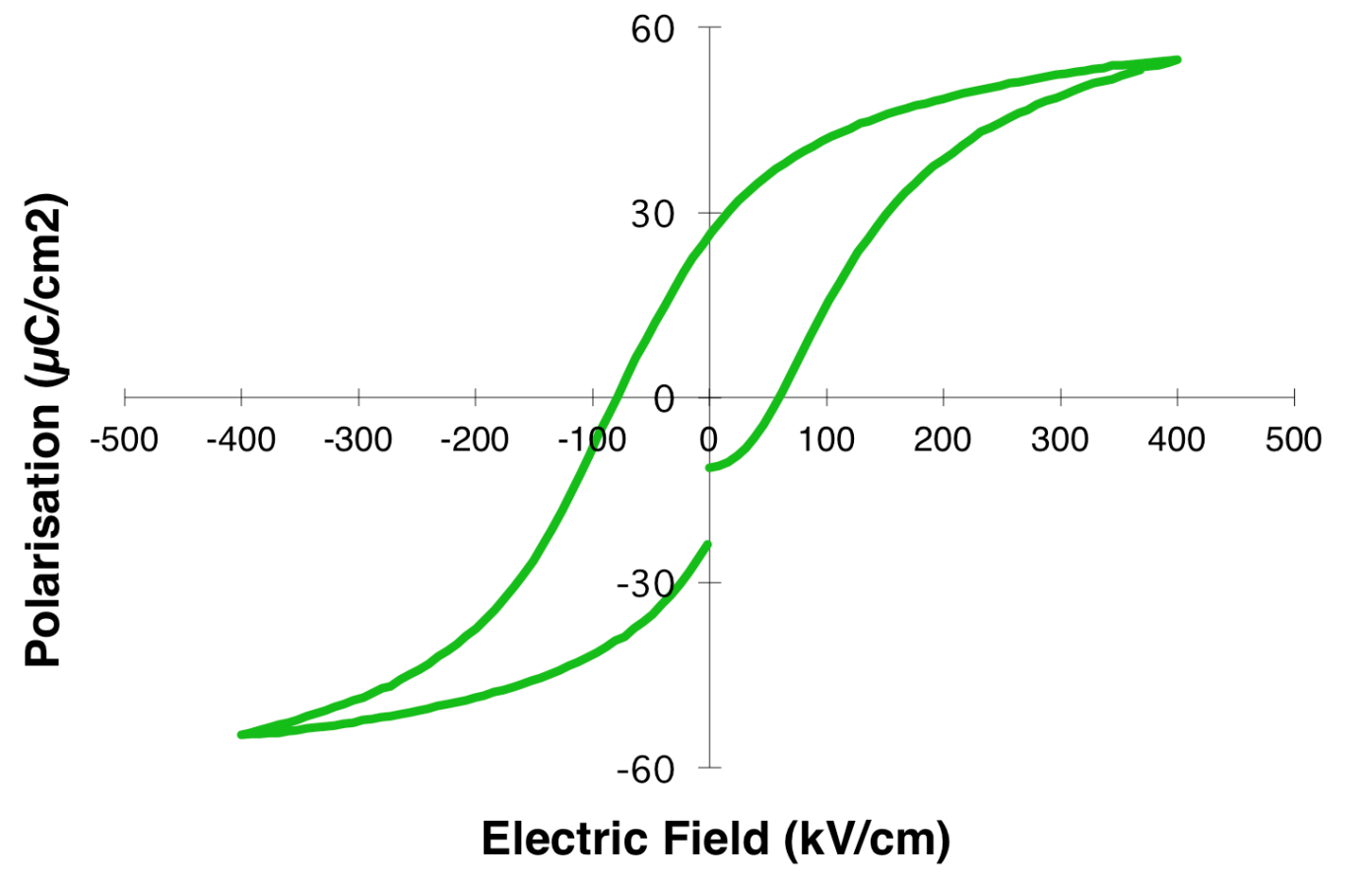

Fig.5: Hysteresis curve for PZT measured on a commercial set up (RT66A from Radiant) in the virtual ground mode, with bipolar drive profile and $0.2 \mathrm{~s}$ for a cycle. The sample had a dielectric constant of 400 and was a bilayer with first $41 \%$ afterwards $72 \%$ of $\mathrm{Zr}$.

\section{CONCLUSIONS}

The sputter method described above is reproducible and makes use of the self stabilization of the $\mathrm{Pb}$ content in the film due to temperature and plasma effects. It allows the growth of well oriented $\mathrm{PbTiO}_{3}$ on $\mathrm{Pt}$ in a wide pressure and temperature range. Preferred orientation is more difficult to obtain for PT grown on $\mathrm{RuO}_{2}$. The permitivity can be varied with different settings of the process parameters. The method was extended to PZT with promising results for compositions up to $\mathrm{PbZr}_{0.7} \mathrm{Ti}_{0.3} \mathrm{O}_{3}$.

\section{ACKNOWLEDGEMENTS}

This work was supported by the CEPF (Swiss Priority Programm on Materials Science).

\section{REFERENCES}

1. K. Sreenivas and M. Sayer, J.Appl. Phys. 64, 1484 (1988).

2. K. Iijima, Y. Tomita, R. Takayama, and I. Ueda, J. Appl. Phys. 60, 361 (1986).

3. R.A. Roy and K.F. Etzold, J.Mater.Res., 7, 1455 (1992).

4. R. Bruchhaus, H. Huber, D. Pitzer, and W. Wersing, Ferroelectrics 127, 137 (1992).

5. H. Maiwa, N. Ichinose, and K. Okazaki, Jpn. J. Appl. Phys., 31, 3029 (1992)

6. K. Hirata et. al., Jpn. J. Appl. Phys., 31, 3021 (1992).

7. C.V.R. Vasant Kumar, R. Pascual, and M. Sayer, J. Appl. Phys. 71, 864 (1992).

8. K. Sreenivas, I. Reaney, T. Maeder, and N. Setter, J. Appl. Phys. 75, 232 (1994).

9. S. Ueno and H. Ishiwara, Jpn. J. Appl. Phys., 31, 2982 (1992).

10. K. Iijima, et.al., J. Appl. Phys., 72, 2840 (1992).

11. K. Reichelt, Vacuum 38, 1083 (1988).

12. J.A. Venables and G.L. Price, in Epitaxial growth part B, edited by J.W. Matthews (Academic Press, New York 1975) pp. 381 - 436.

13. Z.Li, M. Grimsditch, X. Xu and S.-K. Chan, Ferroelectrics 141, 313 (1993). 